Всеволод Владимирович Байбак

\title{
ВОПРОСЫ РЕФОРМИРОВАНИЯ ОБЩИХ ПОЛОЖЕНИЙ РОССИЙСКОГО ГРАЖДАНСКОГО ЗАКОНОДАТЕЛЬСТВА ОБ ОБЯЗАТЕЛЬСТВАХ
}

\section{Вступление}

Пожалуй, ни один раздел гражданского права не славится такой стабильностью и разработанностью, как общие положения об обязательствах. Учитывая давнюю историю развития большинства институтов обязательственного права, впитавших многовековой опыт развития имущественного оборота, кажется, что эта подотрасль в последнюю очередь нуждается в принципиальных изменениях. И, тем не менее, именно концепция реформирования общих положений российского гражданского законодательства об обязательствах (далее - концепция) ${ }^{1}$, занимающая почти две сотни страниц, первой увидела свет среди рабочих документов Совета по кодификации и совершенствованию гражданского законодательства при Президенте Российской Федерации.

Даже первый взгляд на многие положения концепции показывает, какие принципиальные задачи стоят перед законодателем. Во-первых, необходимо произвести тонкую настройку хорошо зарекомендовавших себя институтов, очистив их от выявленных в практике неточностей, двусмысленных положений и неудачных формулировок. Во-вторых, в концепции содержатся ответы на многие болезненные вопросы, ставшие камнем преткновения в применении обязательственно-правовых конструкций. В-третьих, и это, возможно, самое ценное в концепции - законодатель обозначает свое стремление интегрироваться в международное правовое пространство, имплементировать положения, давно и прочно вошедшие в цивилистический оборот за рубежом.

1 Проект Концепции совершенствования общих положений обязательственного права России // Приложение к ежемесячному юридическому журналу «Хозяйство и право» № 3, 2009. 
Нельзя признать, что все эти задачи решаются одинаково удачно. Однако концепция - лишь первый шаг на пути реформы Гражданского кодекса РФ (далее - ГК), за которым должны последовать другие важные шаги и прежде всего - оценка положений концепции юридическим сообществом как в России, так и за ее пределами. Задачей настоящей публикации является ознакомление читателей с некоторыми заметными новеллами, которые ожидают российский имущественный оборот в ближайшем будущем.

\section{Понятие обязательства}

Одним из дискуссионных вопросов в российской цивилистической доктрине является юридическая квалификация правоотношений, связанных с обязанностью возврата полученного по недействительной сделке (далее реституционные правоотношения) и с участием в юридических лицах (далее - корпоративные правоотношения). Данные отношения имеют значительное сходство с обязательствами. Так, они преимущественно носят относительный характер, обеспечивают получение управомоченным от обязанного определенных имущественных благ и пр. Это позволило высшим судебным инстанциям Российской Федерации распространить на реституционные и корпоративные правоотношения действие общих положений об обязательствах. ${ }^{2}$ В то же время в литературе высказывается точка зрения о том, что указанные правоотношения нельзя считать обязательственными. ${ }^{3}$ Так или иначе, но почва для такой дискуссии заложена в действующем законодательстве, которое оставляет открытым вопрос о юридической квалификации корпоративных и реституционных правоотношений.

В концепции предлагается решение данного вопроса. А именно, ст. 307 ГК, в которой содержится определение понятия обязательства, предлагается дополнить положением о возможности применения общих положений об обязательствах к другим определённым правоотношениям, в частности, реституционным и корпоративным, если иное не предусмотрено ГК и иными законами и не вытекает из существа указанных правоотношений. Если данное предложение будет реализовано в законе, на вопрос о том, являются ли данные правоотношения обязательственными будет дан четкий отрицательные ответ.

2 См., напр.: п. 6 Информационного письма Президиума Высшего Арбитражного Суда Российской Федерации от 21 декабря 2005 г. № 102 «Обзор практики применения арбитражными судами статьи 409 Гражданского кодекса Российской Федерации»; Постановление Президиума Высшего Арбитражного Суда Российской Федерации от 8 феевраля 2000 г. № 1066/99.

3 См., напр: Егоров Н.Д. К вопросу о понятии обязательства // Сб. статей к 55-летию Е.А. Крашенинникова. Ярославль, 2006. 
Вместе с тем, такой ход возлагает на разработчиков реформы ГК большую ответственность, ибо от того, насколько адекватно будет описан механизм применения общих положений об обязательствах к реституционным и корпоративным правоотношениям, зависит решение целого ряда актуальных практических проблем. Так, в практике нередко возникает потребность в уступке права требовать возврата исполненного по недействительной сделке (цессии), прекращении данного обязательства новацией или предоставлением отступного, способе исполнения обязательств в рамках корпоративных правоотношений и т.п.

Еще одним заметным изменением, затрагивающим понятие обязательства, является попытка решения проблемы регулирования отношений, складывающихся на этапе, предшествующем заключению гражданско-правового договора (далее - преддогоговорные отношения). В настоящее время данные отношения практически не охвачены Гражданским кодексом. Между тем потребность в том, чтобы стороны цивилизованно строили переговорный процесс, не вводя друг друга в бессмысленный расход времени и средств, весьма велика. Неудачность существующего положения усугубляется еще и тем, что ведущие зарубежные правопорядки весьма успешно решают данную задачу. Вследствие этого возникает весьма болезненный разрыв между представлениями о преддоговорных отношениях российских субъектов гражданского оборота и их зарубежных контрагентов. В концепции намечены лишь общие подходы в решении названной проблемы. А именно, признается возможность возникновения обязательственных правоотношении на преддоговорной стадии в случаях, предусмотренных законом, а также декларируется намерение разработать порядок регулирования названных отношений.

Далее, разработчики концепции заявляют о своем намерении «дать прописку» в ГК такой разновидности отношений, как натуральные обязательства. Данный термин хорошо известен в доктрине гражданского права, но эти отношения до сих пор не получили адекватного отражения в законе. Исходя из этой задачи, предполагается сформулировать следующие правила о натуральных обязательствах:

а) натуральным признаётся обязательство, по которому требования кредитора не подлежат судебной защите;

b) основания возникновения натуральных обязательств, а также условия и порядок отказа в судебной защите требований кредиторов по таким обязательствам определяются ГК и другими законами;

с) в случаях, предусмотренных законом или договором, требованиям кредитора по натуральному обязательству может быть предоставлена судебная защита. 
В целом данный подход заслуживает поддержки, т.к. устраняется весьма существенный пробел в регулировании отношений имущественного оборота. к примеру, именно отсутствие соответствующего нормативного материала несколько лет назад вызвало весьма неоднозначную судебную практику по спорам, связанным с биржевыми сделками. Так, фьючерсные сделки воспринимались как разновидность игры, соответственно не снабжались исковой защитой. ${ }^{4}$ Такое неудовлетворительное положение дел потребовало от законодателя внесения специальных изменений в ГК, однако проблема с натуральными обязательствами в целом осталась нерешенной.

Наконец, особое внимание привлекает попытка решить в концепции проблему конкуренции договорного и виндикационного иска. Всякий раз, когда нарушаются права собственника, передавшего свою вещь во временное владение по договору, возникает проблема выбора собственником способа защиты своих прав - виндикационный иск или договорный. Несмотря на то, что эта проблема получила широкое освещение в цивилистической доктрине, в действующем законодательстве нет ее однозначного решения. В концепции предлагается закрепить для данной ситуации приоритет договорного иска. Это решение в целом заслуживает поддержки, т.к. только такой подход позволит наиболее полно защитить интересы обеих сторон договора и учесть те факторы, которые по определению остаются за рамками рассмотрения виндикационного иска.

\section{Исполнение обязательств}

Среди изменений, которые предполагается внести в главу, посвященную исполнению обязательств, первостепенное значение имеет закрепление принципа добросовестности при исполнении обязательств. Данный принцип в свою очередь должен быть сформулирован столь широко, чтобы охватить и хорошо известный по советскому законодательству принцип сотрудничества сторон при исполнении обязательств. к сожалению, отказываясь от многих одиозных советских принципов регулирования обязательственных отношений, законодатель изъял из ГК и принцип сотрудничества при исполнении обязательств. Между тем потребность в нем, равно как и в глобальном принципе добросовестности, весьма велика. Их нормативное закрепление как соответствует нравственным ожиданиям общества, так и способствует формированию цивилизованной деловой практики. Наконец, они позволяют эффективно 
Вопросы ресормирования общих положений...

минимизировать расходы, связанные с исполнением обязательств, а это особенно актуально в сегодняшнее непростое время.

Продолжая тему расходов, связанных с исполнением обязательства, необходимо упомянуть еще одно общее правило исполнения обязательств, которое должно появиться в ГК: расходы, связанные с исполнением обязательства, относятся на должника, если иное не установлено законом, иными правовыми актами или условиями обязательства или не следует из обычаев делового оборота или иных обычно предъявляемых требований. Несмотря на разумность и даже очевидность такого решения, соответствующая норма в действующем законодательстве отсутствует, и ее появление позволит снять многие проблемы и избежать возникновения споров.

Не столь однозначным выглядит другое предложение разработчиков концпеции - установление общей обязанности кредитора принять исполнение обязательства, предложенное за должника третьим лицом. В действующем законодательстве у кредитора такая обязанность возникает лишь в двух случаях: 1) при возложении исполнения должником на третье лицо; 2) при исполнении третьим лицом по собственной инициативе, если третье лицо подвергается опасности утратить право на имущество должника (ст. 313 ГК). Таким образом, в целом и должник, и кредитор контролируют процесс исполнения обязательства. Если же допустить возможность исполнения обязательства третьим лицом по собственной инициативе как общее правило, могут возникнуть существенные проблемы у обеих сторон обязательства. Так, неясно, как должны защищаться интересы кредитора в ситуации, когда исполнение третьего лица оказалось ненадлежащим. Предъявление требований к должнику выглядело бы неоправданным, т.к. последний не возлагал исполнение. Требовать чего-то от третьего лица также невозможно, ибо оно не несет обязанностей пред кредитором. Такое положение невыгодно и для должника, который по идее не освобождается от своей обязанности пред кредитором, но при этом может впасть в просрочку вследствие того, что кредитор принял исполнение от третьего лица вместо того, чтобы принять его от должника. Наконец, интересы должника могу пострадать от того, что общим последствием исполнения третьим лицом является не возникновение у третьего лица регрессных требований в отношении должника, а переход к третьему лицу прав кредитора по обязательству, которое третье лицо исполнило за должника. Такая конструкция может быть использована недобросовестными третьими лицами, стремящимися к доведению должника до банкротства. Эти и иные соображения требуют еще раз критически осмыслить изменения правил исполнения обязательств третьим лицом, предлагаемые в концепции. 
Важное значение имеет предложение разработчиков зафиксировать момент, в который считается исполненным денежное обязательство при перечислении безналичных денежных средств. В действующем законодательстве закреплены лишь правила относительно исполнения денежных обязательств путем передачи денег, т.е. вещей, определяемых родовыми признаками. Поскольку денежные средства на банковских счетах являются имущественными правами, к безналичным платежам названные правила неприменимы. ${ }^{5}$ В концепции предлагается зафиксировать тот подход, который получил признание в правоприменительной практике: считать моментом исполнения обязательства при безналичном платеже момент зачисления денежных средств на счет банка (а не кредитора!), в котором у кредитора открыт соответствующий счет. Это позволяет снять с кредитора риск ненадлежащих действий банка должника ${ }^{6}$, а с должника - риск ненадлежащих действий банка кредитора. ${ }^{7}$

Наконец, принципиальным представляется изменение режима обязательств, возникающих из двусторонне-обязывающего договора. В ГК есть правило о том, что в таком договоре может быть установлен режим «встречных обязательств» (ст. 328 ГК). Это предполагает, что одна сторона, не получившая исполнения от другой стороны, может возражать против встречного исполнения (exceptio non adimpleti contractis). Однако проблема заключается в том, что в действующем законодательстве режим «встречных обязательств» действует не в любом двусторонне-обязывающем договоре, а только в случаях, когда это специально предусмотрено законом или договором. В концепции предлагается исправить этот недостаток и установить диспозитивное общее правило о том, что одна сторона двусторонне-обязывающего договора не вправе требовать исполнения, не предоставив причитающегося с нее по обязательству другой стороне.

\section{Перемена лиц в обязательстве}

Применительно к переходу прав кредитора к другому лицу разработчики концепции ставят задачу решить целый ряд вопросов, по которым уже сформировалась устойчивая правоприменительная практика, однако в отношении которых в законе до сих пор сохраняется двусмысленность или недосказанность.

5 См. подр.: Рассказова Н.Ю. О деньгах и денежных средствах в гражданском праве // Цивилистические записки: Межвузовский сборник научных трудов. Выпуск 4. М., 2005. С. 162-163. и банк списывает соответствующую сумму, но отправляет ее по иному назначению или вообще не направляет никуда. 
Так, предлагается прямо закрепить возможность уступки части права требования, если обязательство (т.е. предмет обязательства) делимо. ${ }^{8}$ Для неденежных обязательств формулируется еще одно условие - положение должника в результате частичной уступки не должно стать значительно более обременительным. Такой подход используется в Принципах международных коммерческих договоров УНИДРУА 2004 г. (ст. 9.1.4, далее - Принципы УНИДРУА). Однако его безоговорочное заимствование вызывает определенные опасения. В частности, правомерность частичной цессии ставится в зависимость от оценочного критерия «значительно более обременительное» положение должника. Это означает, что судьба цессионной сделки будет зависеть от усмотрения суда в каждом конкретном случае. к сожалению, российская правоприменительная практика не отличается высокой стабильностью. Поэтому решение, предлагаемое в концепции, может негативно отразиться на обороте обязательственных требований, привнеся в него новые судебные риски.

Далее, разработчики намерены включить в ГК положение о возможности уступки будущих требований (т.е. тех, которые еще даже не возникли в момент совершения уступки требования, а не требований с не наступившим сроком исполнения). ${ }^{9}$ Вместе с тем в концепции оставлен открытым вопрос о том, в какой момент такое право считается переданным - в момент совершения цессионной сделки или в момент его возникновения у первоначального кредитора. На наш взгляд, право, которое еще не существует, ео ірso не может и перейти к другому лицу. к тому же при ином подходе невозможно обеспечить полноценное правопреемство в обязательственном правоотношении, а значит, защитить интересы должника и третьих лиц.

Пожалуй, самым заметным изменением в правовом регулировании оборота обязательственных требований является то, что оговорка pactum de non cedendo по денежным обязательствам должна утратить свою силу в отношении третьих лиц. Дело в том, что в настоящее время уступки, совершенные в противоречии с договорными запретами или ограничениями цессии, являются недействительными (п. 1 ст. 388 ГК). Соответственно, право требования просто не переходит к новому кредитору. Однако в международной практике (в частности, в ст. 9.1.9 Принципов УНИДРУА) принят иной подход - уступка денежного требования, противоречащая pactum de non cedendo, действительна, однако должник имеет право взыскать с цедента свои убытки, возникшие вследствие нарушения запрета или ограничения цессии. Аналогичный подход

8 См. п. 5 Информационного письма Президиума Высшего Арбитражного Суда Российской Федерации от 30.10.2007 № 120 «Обзор практики применения арбитражными судами положений главы 24 Гражданского кодекса Российской Федерации».

9 См. п. 4 Информационного письма Президиума Высшего Арбитражного Суда Российской Федерации от 30.10.2007 № 120 «Обзор практики применения арбитражными судами положений главы 24 Гражданского кодекса Российской Федерации». 
закреплен в российском законодательстве применительно к особым случаям уступки, а именно, в рамках договора финансирования под уступку денежного требования (факторинга, ст. 828 ГК). В концепции предлагается распространить такой режим на все сделки уступки денежных требований. По-видимому, разработчики исходят из мысли о том, что в денежных обязательствах значение личности кредитора для должника столь мало, а потребность в интенсификации оборота таких требований столь велика, что следует переступить через принцип pacta sunt servanda, дав должнику возможность защитить свои нарушенные права и охраняемые законом интересы.

Заслуживает упоминания попытка разработчиков концепции решить проблему уступки требований в солидарных обязательствах. Дело в том, что солидарный кредитор, получивший исполнение от должника в полном объеме, обязан возместить причитающееся в другим солидарным кредиторам (п. 4 ст. 326 ГК). Если солидарный кредитор недобросовестен, если ему угрожает банкротство, перспективы получения своей части остальными солидарными кредиторами весьма туманны. В ситуации, когда солидарное требование уступается одним из кредиторов постороннему лицу, риски остальных кредиторов могут возрасти. Одним из вариантов решения названной проблемы могло бы стать введение права преимущественного приобретения таких требований другими солидарными кредиторами на условиях, предлагаемых третьему лицу. ${ }^{10}$ Однако в концепции отсутствует какое-либо конкретное решение поставленной проблемы.

Наконец, разработчики концепции обозначили проблему оборота обязательственных требований, которая в российском законодательстве вообще не решена: возможность добросовестного приобретения обязательственного требования от неуправомоченного отчуждателя. В настоящее время такие положения действуют лишь в отношении оборота вещей, т.е. телесных объектов (ст. 302 ГК), и к обязательственным требованиям неприменимы. Потребность же в формировании таких правил для бестелесных оборотоспособных ценностей (в частности, прав по обязательствам) весьма велика. Первые шаги в решении этой проблемы законодатель уже сделал, допустив возможность добросовестного приобретения от неуправомоченного отчуждателя доли в уставном капитале общества с ограниченной ответственностью (п. 17 ст. 21 Федерального закона от 08.02.1998 № 14-Ф3 «Об обществах с ограниченной ответственностью»). Логично было бы продолжить данную политику применительно к иным имущественным правам - обязательственных требований. ${ }^{11}$

10 См.: Байбак В.В. Обязательственное требование как объект гражданского оборота. М., 2005. С. 91-92.

11 См.: Байбак В.В. Обязательственное требование как объект гражданского оборота. С. 159-181. 
В отношении перевода долга заслуживает упоминания предложение внести определенность в вопрос о судьбе обеспечений. А именно, если первоначальный должник освобождается от обязательства, то это освобождение должно распространяться на все предоставленные им залоговые обеспечения, если только он не передает предмет обеспечения новому должнику. кроме того, по мнению разработчиков концепции, обеспечение исполнения обязательства, предоставленное любым третьим лицом, должно прекращаться, если только такое лицо не согласится отвечать за нового должника. Данные новеллы заслуживают поддержки, ибо являются логичным продолжением принципа акцессорности обеспечительных обязательств.

Также представляется целесообразным еще одно предлагаемое нововведение - допустить возможность дачи кредитором согласия на перевод долга под условием сохранения за первоначальным должником определенной ответственности за исполнение обязательства - солидарной или субсидиарной. Это позволит более эффективно управлять рисками кредитора, которые изменяются при переводе долга.

\section{Ответственность за нарушение обязательств}

Прежде всего, обращает на себя внимание попытка разработчиков концепции дать отсутствующее ныне в законе определение того, что следует понимать под «полным возмещением убытков». Следуя подходам, принятым в зарубежной и международной практике, концепция уточняет: полное возмещение убытков означает, что кредитор должен быть поставлен в положение, в котором он находился бы, если бы обязательство было исполнено должником надлежащим образом. По мысли разработчиков концепции, это должно воспрепятствовать попыткам недобросовестных кредиторов получить неосновательное обогащение за счет должника, используя механизм возмещения убытков.

Весьма заметным изменением режима ответственности за нарушение обязательств является введение критерия предвидимости убытков для ограничения ответственности должника. Данный критерий в том или ином виде присутствует во многих правопорядках и международных актах. ${ }^{12}$ В концепции предлагается установить, что должник, допустивший нарушение договорного обязательства, не должен возмещать ущерб, который он не предвидел или не мог разумно предвидеть при заключении договора как вероятное последствие его неисполнения. Данное предложение в целом заслуживает поддержки, од-

12 Ст. 1225 ГК Италии, ст. 1150 ГК Франции, ст. 113 Закона о договорах Китайской Народной Республики, ст. 7.4.4 Принципов УНИДРУА и др. 
нако такая формулировка явно недостаточна для полноценного применения критерия предвидимости. В частности, оставлен открытым вопрос о том, что должно оцениваться при применении критерия предвидимости - предвидение должником размера убытков или их типа. Не определено, на ком лежит бремя доказывания (не)предвидимости убытков - на должнике или на кредиторе. Необходимо уточнить, какие параметры должны приниматься во внимание при оценке предвидимости - субъективные представления должника и(или) информация, доступная любому субъекту оборота. ${ }^{13}$ Вместе с тем, в концепции не упоминается условие применения критерия предвидимости, содержащееся во многих иностранных кодексах и международных актах - ответственность должника не может быть ограничена, если он нарушил договор умышленно или по грубой неосторожности. ${ }^{14}$ Если рассматривать такое умолчание как нежелание российского законодателя вводить данное условие в ГК, то это заслуживает поддержки, ибо иной подход чреват осложнениями. ${ }^{15}$

Весьма важное значение имеет еще одно положение концепции - закрепление общих правил об абстрактном методе определения убытков. к сожалению, в действующем законодательстве абстрактный метод исчисления убытков применяется лишь в виде исключения в отдельных видах обязательств. Например, положения о возмещении разницы между ценой прекращенного договора и средней рыночной ценой закреплены лишь в нормах о договоре поставки (ст. 524 ГК). Между тем значение этих положений, как отмечалось в литературе, выходит далеко за пределы отношений поставки. ${ }^{16}$ Поэтому намерение разработчиков концепции придать этому подходу общий характер стоит только приветствовать.

Наконец, необходимо отметить еще одно предложение, направленное на сближение российского гражданского законодательства с международными стандартами. В настоящее время одной из основных проблем при применении такой меры ответственности, как взыскание убытков, является доказывание их точного размера. Если кредитору удается доказать сам факт наличия убытков, но не получается обосновать их точный размер, суд вынужден отказать в иске полностью. В международной и зарубежной практике эта проблема решается посредством того, что суду в таких ситуациях представляется право самостоятельно определить размер убытков. ${ }^{17}$ Аналогичное право предлагается предо-

13 См. подр.: Байбак В.В, Предвидимость убытков как критерий ограничения ответственности за нарушение договора. Вестник Высшего арбитражного суда РФ. № 5. 2009.

14 См., напр: ст. 9:503 Принципов европейского договорного права, ст. 1225 ГК Италии, ст. 1150 ГК Франции.

15 См. подр.: Байбак В.В, Предвидимость убытков как критерий ограничения ответственности за нарушение договора. С. 68-69.

16 Брагинский М.И., Витрянский В.В. Договорное право. книга первая: Общие положения. 2-е изд. М., 2005. C. 655-656.

17 См., напр., п. 3 ст. 7.4.3. Принципов УНИДРУА. 
ставить и российским судам, ограничив его принципами разумности, справедливости и соразмерности ответственности допущенному нарушению с учетом всех обстоятельств дела. С одной стороны, подобное нововведение позволит защитить кредиторов в целом ряде случаев, когда они действительно нуждаются в защите. С другой стороны, в этом подходе заложена такая доля судейского усмотрения, что степень определенности данной нормы стремится к нулю. Насколько удачно будет складываться практика применения указанного подхода покажет будущее, однако потенциально предлагаемая новелла может принести положительные результаты. 


\section{QUESTIONS REGARDING THE GENERAL REFORM OF THE RUSSIAN LEGISLATION ON OBLIGATIONS}

This paper addresses major amendments to the general rules of Russian Civil code on obligations. Those amendments were prepared in order to harmonize Russian law of obligations and bring it into compliance with modern legislative standards. Amendments shall affect all major sections of the Russian Civil code relating to the obligations. Namely, the definition of an obligation, the rules specifying the process of performance of the obligations. Massive modifications shall be inserted into the chapter on assignment of rights and debts, providing for totally new rules on assignment of future rights, partial assignment, assignor's warranties to the assignee and the like. Less significant amendments shall be inserted into the rules on responsibility for breach of obligations, however providing for important rules on concrete and abstract damages, definition of the principle of full compensation, liability for breach of monetary obligations.

Key words:

Law of obligations, performance of obligations, assignment, responsibility. 